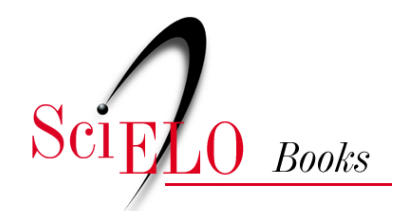

\title{
Capítulo VII - Saberes tradicionais e o desafio da multiculturalidade nas instituições de ensino
}

\author{
Mariana Martins da Costa Quinteiro \\ Lana Cláudia Fonseca
}

\section{SciELO Books / SciELO Livros / SciELO Libros}

QUINTEIRO, M.M.C., and FONSECA, L.C. Saberes tradicionais e o desafio da multiculturalidade nas instituições de ensino. In: SANTOS, M.G., and QUINTERO, M., comps. Saberes tradicionais e locais: reflexões etnobiológicas [online]. Rio de Janeiro: EDUERJ, 2018, pp. 148-167. ISBN: 978-85-7511-4858. https://doi.org/10.7476/9788575114858.0009.

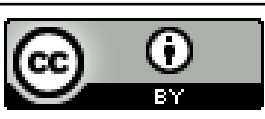

All the contents of this work, except where otherwise noted, is licensed under a Creative Commons Attribution 4.0 International license.

Todo o conteúdo deste trabalho, exceto quando houver ressalva, é publicado sob a licença Creative Commons Atribição 4.0.

Todo el contenido de esta obra, excepto donde se indique lo contrario, está bajo licencia de la licencia $\underline{\text { Creative }}$ Commons Reconocimento 4.0 . 


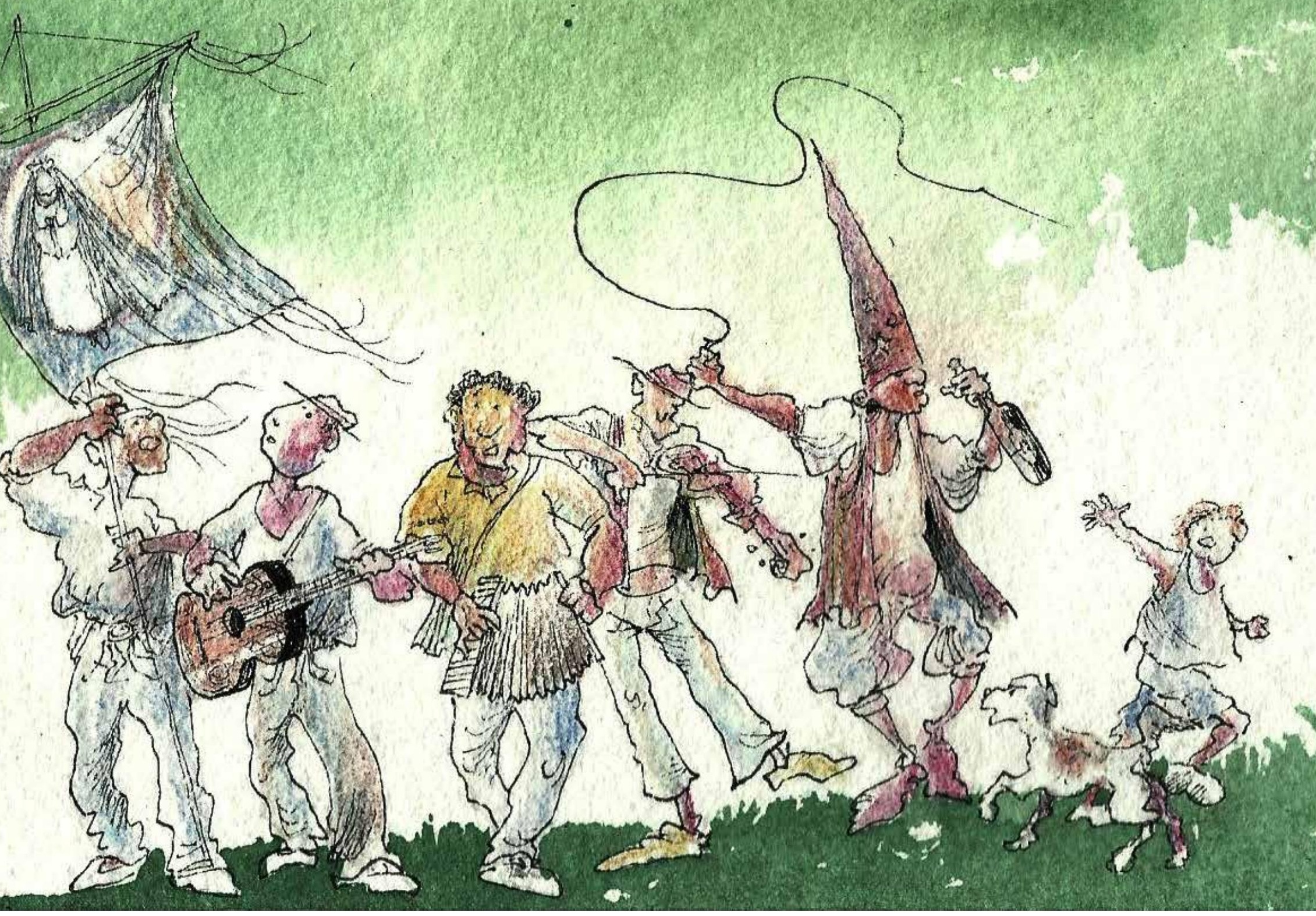




\title{
CAPITULO VII
}

\section{Saberes tradicionais e o desafio da multiculturalidade nas instituiçồes de ensino}

\author{
Mariana Martins da Costa Quinteiro \\ Lana Cláudia Fonseca
}

\begin{abstract}
A ciência pode classificar e nomear os órgãos de um sabiá, / mas não pode medir seus encantos./ A ciência não pode calcular quantos cavalos de força/ existem/ nos encantos de um sabiá./ Quem acumula muita informação perde o condão de adivinhar: divinare./ Os sabiás divinam.

Manoel de Barros, Livro sobre Nada
\end{abstract}

\section{Caminhos de entendimento do mundo natural}

É inerente ao homem a busca constante pelo conhecimento do mundo ao seu redor, seja ele físico, social ou espiritual (Cobern, 1996). Como consequência dessa busca, os homens estão sempre atribuindo significados e símbolos ao mundo em que vivem e às suas ações, isto é, estão sempre produzindo cultura, cada qual comportando uma interpretação particular de natureza que constitui um elemento importante da visão de mundo de um povo (Baptista, 2010). Na tentativa constante de compreender a si mesmo e ao mundo que o cerca, a realidade na qual está inserido e da qual é parte fundamental, o ser humano vem criando, incessantemente, formas de conhecer. Este conhecimento seria a maneira mais apropriada de, descrevendo a realidade, apropriar-se dela e, assim, controlar a si mesmo e ao meio.

Em nossa sociedade moderna, a palavra conhecimento tornou-se sinônimo de conhecimento científico. Conhecer passou a ser, desde o surgimento da ciência: descrever a realidade a partir dos pressupostos impostos 
por ela. Entretanto, o conhecimento sempre esteve aliado à história humana, visto que, desde nosso surgimento ancestral, tentamos conhecer para, dentre outros objetivos, entendermos e controlarmos nossa vida. Nesse curso, dividimos as sociedades em grupos que dominam os conhecimentos produzidos cientificamente, e grupos que não conhecem, ou melhor, que dominam um conhecimento não válido, tido como senso comum, ou, quando muito, denominado de folclórico.

Nesse contexto, o conhecimento científico representa "um" dos muitos caminhos para o entendimento do mundo natural, havendo outros meios cognitivos e explicativos, como o das comunidades tradicionais (Southerland, 2000). Endossando essa discussão, diferentes designações do "saber" são encontradas na literatura, como o "tradicional", o "popular" e o "escolar". O saber tradicional pode ser observado como aquele oriundo das comunidades tradicionais - grupos indígenas, quilombolas, caiçaras, ribeirinhos, extrativistas etc. -, percorrendo caminhos por vezes coincidentes e por outros concorrentes com o saber acadêmico, pois os diferentes conhecimentos são fruto de um processo de "circularidade" influenciando e sendo influenciados mutuamente (Morin, 1996).

Diegues e Arruda (2001) definem esse tipo de conhecimento como o "saber" e o "saber-fazer" a respeito do mundo natural e sobrenatural, gerados no âmbito da sociedade não urbana/industrial. Estabelecidas através de informações orais, por meio de "contação de casos", de parcerias em trabalhos conjuntos, na realização de mutirões, cantigas e de tempo de permanência entre membros jovens e mais idosos dessas comunidades, essas formas de conhecimento são consideradas por diversos autores, no campo das etnociências, como estando sob ameaça. Apesar de comportarem uma dinâmica relativa ao próprio mundo natural e não estarem resignadas a serem imutáveis ao longo das gerações, muitos são os desafios para sua permanência no mundo atual.

O saber popular, analogamente, é definido como aquele fruto da produção de significados das camadas populares da sociedade, ou seja, as classes dominadas do ponto de vista econômico e cultural, que inclui práticas sociais cotidianas e a necessidade de desenvolver mecanismos de luta pela sobrevivência (Lopes, 1999).

Chassot (2001) define o saber escolar como aquele que a escola transmite e, para o autor, a própria ação de transmitir já o descaracteriza, pois se estabelece a diferença entre o produzir e o transmitir. A escola defronta-se com 
duro questionamento (que ela geralmente desconhece) quando se diz que a mesma não é produtora do conhecimento, e sim reprodutora ou apenas transmissora do saber, o que pode ser mitigado por sua contextualização.

As formas de apropriação e transmissão desses diferentes modos do "saber" igualmente os caracterizam e distinguem os meios de sua perpetuação ao longo do tempo. Nesse sentido, muitos aspectos são mais óbvios, como as tradições orais e os registros literários, enquanto outros são difíceis até mesmo de serem discutidos, pois são adotados de forma inconsciente, como as posturas corporais. Tassinari (2001) discute que, entre a oralidade e a escrita há um grande número de situações intermediárias nas quais não prevalecem nem a palavra dita nem os signos linguísticos, mas uma articulação entre ambos, de cunho estético. Soma-se a essa discussão o conceito de "tradições iconográficas", em que a memória social é elaborada e transmitida por intermédio de imagens e enunciações rituais, como discute Severi (2009). O autor considera que focalizando o poder da imagem e da gestualidade para a produção de uma memória coletiva, poderemos mais facilmente compreender como as tradições podem ser transmitidas quase sem recurso à palavra.

Nesse âmbito, a preocupação com a não consideração das especificidades culturais e dos saberes populares nas instituições de ensino é um tema que vem sendo alvo de atenção. Charlot (2000) cita diversos exemplos de reivindicações de consideração da cultura local no ensino formal por todo o mundo, incluindo o Brasil, onde se desenvolve um forte movimento pelo reconhecimento das raízes africanas e indígenas da cultura brasileira. Nessa situação, afirma o direito de cada um ser educado em sua cultura. Por um lado, trata-se de uma afirmação de princípio, a do direito de cada um à diferença cultural e a uma identidade enraizada em suas origens. Por outro, uma exigência de eficácia, já que uma educação que não leva em conta as raízes do educando a mergulha em contradições que podem acarretar o fracasso do processo de aprendizagem.

\section{A construçăo do saber ambiental}

A atual demanda da sociedade no campo do ensino se dá por aprendizagens contínuas e complexas, que exigem um redimensionamento do campo educativo, no sentido de interagir mais com as realidades locais 
e globais e reproduzir menos os modelos simplificadores e simplistas vigentes. Novas propostas de currículos devem propor espaços dedicados ao estudo de diversos subsistemas da realidade socioambiental. Como propõe Luzzi (2003), devemos internalizar a dimensão ambiental através de um "diálogo de saberes", por meio do contato entre o conhecimento popular e o conhecimento científico, que produzirá um conhecimento, fruto da circularidade de ambos, impregnado da dialogicidade, fundamental ao processo pedagógico.

Como um reflexo da sociedade atual em que nos encontramos, o conhecimento produzido encontra-se pouco articulado com situações cotidianas que vivenciamos. A fragmentação do saber, representada pelas especializações do conhecimento, aprofundou a compreensão das partes. Contudo, o ambiente é também uma unidade que precisa ser compreendida de forma integral e é através de um conhecimento transdisciplinar que poderemos assimilar plenamente o equilíbrio dinâmico do ambiente (Guimarães, 1995).

Nesse contexto, a educação ambiental vem sendo definida como inter e transdisciplinar, orientada para a resolução de problemas locais, participativa e comunitária, criativa e ativa. É definida, muitas vezes, como transformadora de valores e atitudes através da construção de novos hábitos e conhecimentos, criadora de uma nova ética, sensibilizadora e conscientizadora para relações integradas ser humano/sociedade/natureza objetivando o equilíbrio local e global, como forma de obtenção da melhoria da qualidade de todos os níveis de vida.

Assim, a sociedade deposita sobre as instituições de ensino e pesquisa a esperança de que sejam vanguarda do desenvolvimento, procurando em suas produções a sinalização de rumos, o sensoriamento de tendências e das oportunidades (Demo, 1993). Realizar investigações que atendam aos interesses e demandas da sociedade é uma questão que deveria ser intrínseca aos currículos educacionais. Para esse autor, pesquisa é questão de atitude processual cotidiana, devendo haver o encontro propício da qualidade formal e política, tornando o conhecimento acadêmico mais educativo, científico e menos alienado. A legitimidade retórica das instituições de ensino está em que se concebem a si mesmas como agentes que internalizam os problemas sociais e lhes oferecem soluções no campo do conhecimento e da formação de agentes de transformação social ou de serviço à sociedade (Riojas, 2003). 
Dessa forma, Luzzi (2003) sugere que deveríamos começar a sugerir esboços com respeito a nossas perguntas iniciais: que necessidades de valores, destrezas, conhecimentos e habilidades têm a humanidade para sobreviver e desenvolver-se? Quais deveriam ser, nesse sentido, os interesses que constituem o nosso saber ambiental? Que recorte do saber existente permite superar o fracionamento da informação? As respostas provisórias a essas perguntas, segundo o autor, nos revelaram as estruturas curriculares possíveis de se implementar, longe dos currículos estruturados em disciplinas ou em áreas fracionadas por sua vez em disciplinas; perto da realidade, trabalhando sobre os fenômenos problemáticos e as potencialidades ambientais regionais e locais, porém sem descuidar das relações entre os seus diversos subsistemas.

Assim, poderemos construir espaços escolares mais orgânicos em que os diversos conhecimentos sejam considerados válidos e utilizados como matéria-prima no processo ensino-aprendizagem.

\section{Os espaços multiculturais}

Os espaços das salas de aula não são uniformes do ponto de vista cultural; isto é, não apenas o saber científico, representado pelos professores, encontra-se presente nessa ocasião. Ao contrário, nelas transitam culturas outras, representadas pelos estudantes, como a de sociedades tradicionais (Cobern, 1996), devendo os professores estar atentos às diversas concepções prévias dos estudantes, ou seja, aos conhecimentos populares que circulam nas salas de aula, para que possam direcionar as suas aulas às necessidades individuais e coletivas, nas sociedades e comunidades onde vivem. Nisso consiste a visão das salas de aula como espaços multiculturais, fundamentais para se superar possíveis dificuldades na comunicação, materializando um espaço dialógico, onde os conhecimentos dos alunos e dos grupos aos quais representam, embora diferentes das concepções científicas, sejam reconhecidos e valorizados. Especialmente no caso daqueles estudantes provenientes de meios culturais nos quais a ciência não faz parte de seu cotidiano, como os estudantes oriundos de comunidades tradicionais (Baptista, 2010), o diálogo entre esses conhecimentos se torna fundamental. 
O que pode ser observado nos espaços formais de educação é a substituição dos saberes tradicionais pelos científicos, e não a consideração daquele ou o diálogo de ambos, muitas vezes, gerando conflitos de conceitos que resultam ora em diminuição e desvalorização de sua identidade, ora em não validação e aplicação dos conhecimentos acadêmicos em seu cotidiano. Muitos conteúdos explicativos só fazem sentido e podem ser compreendidos nas especificidades históricas e culturais em que são gerados. Sua desvalorização no interior dos espaços escolares se torna um dos impedimentos dos processos de ensino-aprendizagem.

Mesmo havendo tentativas de valorização da diversidade cultural nas escolas por parte das políticas públicas da educação brasileira, é lamentável o fato de que as realidades das escolas para as sociedades tradicionais ainda insistam na transmissão dos conhecimentos científicos como os únicos válidos (Baptista, 2010). Não se busca aqui alguma forma de hierarquização ou de priorização de um tipo de saber, mas a ampliação de modos de se observar o mundo e a coletividade, valorizando caracterizações culturais específicas.

A discussão ainda se complexifica, pois, mesmo dentro de uma determinada comunidade, o conhecimento não é homogêneo, havendo aqueles específicos aos homens, às mulheres e às diferentes categorias com as quais esses atores sociais se reconhecem, como "parteiras", "benzedeiros", "erveiros", "mateiros", "tropeiros", "carvoeiros", entre outros. Soma-se a importância da família na transmissão desse conhecimento, onde as novas gerações aprendem com as mais antigas, tanto em espaços informais quanto em "formais", como a roça, a mata, a cozinha, o quintal e na presença de ferramentas específicas como moinhos e monjolos. E, ainda, as particularidades das formas de conhecimento ditas "simbólicas" ou "folclóricas", como as "doenças culturais" (como "quebranto", "vento-virado", "olho-gordo", "espinhela-caída” etc,), as "simpatias” e os personagens "mitológicos", assim designados por não se encontrar na academia uma correspondência imediata à sua existência.

Essa valorização exclusiva da ciência nos espaços escolares acaba resultando na exclusão de outros saberes e impedindo a materialização de processos pedagógicos dialógicos.

A consideração desses conhecimentos tão minuciosos requer uma interpretação e consideração muito detalhada. No caso dos saberes ambientais, por exemplo, cada zona ecológica específica da paisagem, sim- 
bologia e ator social determinado é capaz de oferecer um universo rico de detalhes com o qual o conhecimento acadêmico pode dialogar. Dessa forma, o encontro propício dessas sabedorias, científicas e populares, pode possibilitar o abandono da ideia negativa de ameaça ou perda dos saberes tradicionais, favorecendo a concepção de ressignificação de ideias, proporcionada por esse diálogo e tão valiosa para as constantes mudanças por que passam tanto o ambiente quanto às sociedades. Como afirma Perrelli (2008), a força do conhecimento tradicional reside, justamente, na sua capacidade de se adequar ao mundo atual, além da autonomia que proporciona às populações de onde vem.

Muitas vezes a própria população dita tradicional requer e reivindica o chamado ensino formal, representado pelas instituições de ensino, em diferentes níveis. Essa necessidade é identificada pela vontade de inserção dos seus filhos no processo educacional, procurando uma maior inclusão social. Entretanto, há o contraponto imediato da exclusão do entorno, com o estabelecimento de espaços claramente divididos entre o cotidiano saber da comunidade e o que é abordado nesses locais, considerados como essenciais para a formação dos mais novos; o sentido de comunidade tradicional vai sendo diluído enquanto a escola, símbolo do ensino formal, do "externo", traz a pretensa inclusão cidadã (Paré et al., 2007).

Dessa forma, o saber acadêmico, compulsório pelo viés do ensino formal desde a primeira infância, apresenta o sentido de progresso, de uma lógica racional "necessária" para a formação da visão crítica e para a construção de escolhas conscientes e comprometidas com o desenvolvimento para a liberdade. Essa duvidosa "necessidade", ainda que confirmada por uns mostra-se indubitavelmente insuficiente.

\section{Contribuiçồes do diálogo de saberes}

Como nenhuma outra área do conhecimento humano, as questões ambientais vieram a suscitar nas sociedades, pelas consequências do metabolismo de suas atividades econômicas sobre os sistemas naturais, a discussão das influências de vizinhanças, a avaliação suprafronteiriça de suas atitudes, decisões e procedimentos e a mudança de paradigmas: do paradigma social de uso infinito dos recursos para o novo paradigma do desenvolvimento sustentável (Dias, 2000). 
Apesar da grande polêmica em torno do conceito e das estratégias do que hoje se convencionou denominar "sustentabilidade", é consenso o prisma da multidimensionalidade dessa questão. Definir o ferramental metodológico para viabilizar e implementar a "sustentabilidade" é um grande desafio. A aplicação prática desse conceito passa pela premissa do "manejo sustentável", cujos exemplos são abundantes em grupos humanos estreitamente ligados à natureza.

A acumulação de informações sobre uso de recursos naturais por populações tradicionais tem oferecido aos cientistas modelos de uso sustentável desses mesmos recursos (Albuquerque, 1997; 1999). Pesquisas nessa área podem subsidiar trabalhos sobre usos sustentáveis da biodiversidade através da valorização e do aproveitamento do conhecimento empírico das sociedades humanas, a partir da definição dos sistemas de manejo, incentivando a geração de conhecimentos científicos e tecnológicos voltados para o uso sustentável dos recursos naturais (Fonseca-Kruel e Peixoto, 2004).

O manejo em regime de rendimento sustentável, ou manejo sustentável, é definido por Pavan-Fruehauf (2000) como a forma que trata de estabelecer os parâmetros básicos para definição "do que extrair" (quais espécies), "quanto extrair" (quantidade de biomassa), "quando extrair" (ciclos de colheitas) e "como extrair" (forma de extração do indivíduo e dinâmica da comunidade vegetal). Dessa forma, o manejo sustentável seria um instrumento para a obtenção de métodos necessários à intervenção racional sobre os recursos naturais.

As formas de conhecimento guiadas por critérios de validade locais, fortemente vinculadas aos contextos nos quais foram produzidas, pode constituir peça-chave na observação e intervenção do mundo natural (Quinteiro, 2013). Diversos autores estimulam, assim, o diálogo de saberes nos currículos escolares e acadêmicos. Trata-se de se superar uma visão de mundo etnocêntrica aqui deixada desde a época da colonização, onde a exploração e a espoliação imperavam; de negar toda lógica e conhecimento que não seja o nosso; de pesquisar não "sobre" outras culturas, mas "com" outras culturas (Perrelli, 2008), dando voz a grupos historicamente silenciados. 


\section{Caminhos de um currículo multicultural}

Até que ponto as instituições de ensino formais poderão e deverão remedar a ação pedagógica tradicional é uma das questões mais pertinentes e sobre a qual há muita divergência de opiniões. $\mathrm{O}$ consenso reside no fato de que é necessário um redimensionamento da educação no sentido de dialogar com as realidades vigentes e com situações socioambientais locais concretas.

Entretanto, uma vez estando dentro do contexto de responsabilidade social e complexidade das atuais questões ambientais, mais um desafio é enfrentado pelas pesquisas científicas que buscam o retorno de seus resultados: a ausência de metodologias complexas de abordagem dos temas (Quinteiro e Moraes, 2012).

A construção dos currículos nas escolas vem, historicamente, sendo pautada por uma lógica tradicional que se embasa na reprodução de um grupo de conhecimentos que não leva em consideração os saberes oriundos dos grupos aos quais os alunos pertencem. Esse apagamento é fruto de uma hierarquização que acaba por valorizar os conhecimentos científicos em detrimento de conhecimentos tradicionais e populares que circulam nas escolas. Vivemos um momento em que diversas instâncias da sociedade encontram-se mergulhadas em uma crise, dentre as quais podemos destacar a crise socioambiental. A visão de mundo oferecida pela ciência moderna, que se constituiu em bases cartesianas e newtonianas, não consegue mais explicar a realidade, tendo se tornado obsoleta para dar conta de diversos conceitos:

Vivemos hoje num mundo globalmente interligado, no qual os fenômenos biológicos, psicológicos, sociais e ambientais são todos interdependentes. Para descrever esse mundo apropriadamente, necessitamos de uma perspectiva ecológica que a visão de mundo cartesiana não nos oferece. (Capra, 1982, p. 14)

Desde o momento em que a revolução científica substituiu a visão orgânica da natureza pela comparação do mundo com uma máquina, através de Descartes e Newton, a sociedade ocidental passou a se constituir de forma diferente. Podemos perceber que os currículos escolares 
não dão conta dessa visão interligada de ambiente e ainda encontramos, nas escolas, matrizes que vão priorizar uma lógica fragmentada.

Estamos passando por um momento histórico em que é necessário rever as diversas características de nossa sociedade, dentre elas a forma como as instituições de ensino materializam conhecimentos que são necessários ao desenvolvimento de nossa vida, por meio da compreensão de nosso estar no mundo.

Contudo, no que diz respeito aos conhecimentos relacionados às temáticas ambientais que circulam, por exemplo, nos grupos tradicionais, percebemos que a lógica excludente que a ciência implantou em nossa sociedade acaba por priorizar um único caminho de construção de currículos:

[...] a ideia de que o método científico é a única abordagem válida do conhecimento; a concepção do universo como um sistema mecânico composto de unidades materiais elementares; a concepção da vida em sociedade como uma luta competitiva pela existência; e a crença do progresso material ilimitado, a ser alcançado através do conhecimento científico e tecnológico (Capra, 1982, p. 28).

Esse currículo corrobora a hegemonia científica e destaca a ciência como um único caminho para a racionalidade, como nos lembra Boaventura de Sousa Santos (1993, p. 30):

Dos meados do século XIX até hoje a ciência adquiriu total hegemonia no pensamento ocidental e passou a ser socialmente reconhecida pelas virtualidades instrumentais de sua racionalidade, ou seja, pelo desenvolvimento tecnológico que tornou possível. A partir deste momento, o conhecimento científico pôde dispensar a investigação das suas causas como meio de justificação. Socialmente passou a justificar-se, não pelas suas causas, mas pelas suas consequências.

Com isso, o conhecimento científico ganhou uma posição de destaque que passou a divulgá-lo como verdade, como dogma, e passou a negar e a tratar como erro o modo como as classes populares, os grupos tradicio- 
nais, teoricamente não detentores deste conhecimento "oficial", entendem e explicam o mundo.

Nesta ruptura, o conhecimento científico não resgatou o conhecimento popular e estabeleceu "o divórcio entre sujeito e objeto, produtor e produto, em nome da suposta universalidade do outro, do mais 'avançado" (Martins, 1989, p. 114). A ciência ganhou o status de verdade e pareceu esquecer que ela mesma é uma "prática social do conhecimento" (Santos, 1993, p. 11).

Assim torna-se clara a afirmação de Boaventura: "a eficácia social dos fatos individuais ou naturais é determinada pelo sistema de relações sociais e históricas em que se insere" (1996, p. 35). Como podemos pensar em currículos que levem em consideração, em sua construção, a lógica de interpretar a realidade dos grupos populares? Como pensar em alterar o sentido que esses currículos materializam ao fragmentarem os conhecimentos e excluírem de sua construção saberes que não são considerados válidos? Como mudarmos a lógica e pensarmos em currículos que permitam às salas de aula se constituírem em espaços multiculturais, em que todos os conhecimentos que nela circulam sejam considerados válidos e importantes para a constituição da visão de mundo dos sujeitos?

Uma primeira reflexão a ser realizada diz respeito à valorização dos conhecimentos produzidos pelos grupos populares, reorganizando a lógica de que conhecimentos "verdadeiros" devem se embasar na objetividade, na quantificação, no rigor. Os grupos populares produzem conhecimentos que contêm lógicas próprias e sentidos de resistência que, dadas as condições, podem desenvolver-se e transformar-se em armas de luta que produzem formas de ser e estar no mundo.

O currículo gera uma tal relação entre saber e poder que, através de sua linguagem, de seu discurso, exclui aqueles que não se orientam pelos princípios de sua racionalidade formal e instrumental. Assim, limita os que têm como um dos maiores instrumentos de relação com o mundo sua experiência, sua cultura oral, reforçando a visão, até mesmo dos próprios integrantes destas classes de que não "sabem". Como nos diz Freire (1987, p. 50):

De tanto ouvirem de si mesmos que são incapazes, que não sabem nada, que não podem saber, que são enfermos, indolentes, que 
não produzem em virtude de tudo isto, terminam por se convencer de sua 'incapacidade'. Falam de si como os que não sabem e do 'doutor' como o que sabe e a quem devem escutar.

É essa a realidade que temos encontrado nas escolas, a constituição da sala de aula como um espaço que se pauta em um monólogo, que apaga e exclui conhecimentos que não sigam a mesma ordem e lógica dos produzidos pelos grupos hegemonicamente dominantes na sociedade.

Mas, podemos encontrar brechas por meio das quais construiremos possibilidades de materializarmos currículos que resgatem a dialogicidade entre os conhecimentos e assumam a circularidade entre eles. Caminhar no sentido de uma nova relação entre a ciência e saberes populares é promover uma ruptura de paradigmas que pode trazer soluções à atual lógica do mundo em que vivemos e que reduziu "tudo aquilo que é social, humano e biológico à lógica das máquinas artificiais" (Morin, 1996, p. 110). É preciso superarmos esse etnocentrismo científico e fazermos uma relação em que "qualquer deles é feito do outro e ambos fazem algo de novo" (Santos, 1993, p. 43).

Um primeiro movimento nesse sentido é assumirmos que todos os sujeitos produzem conhecimento e, portanto, todas as pessoas constroem lógicas de interpretação da realidade. Pessoas pertencentes às comunidades tradicionais produzem cotidianamente interpretações e visões de ambiente e de como se relacionam com ele.

Ao assumirmos, na construção de currículos, numa perspectiva multicultural, que há diferentes formas de compreender e explicar os fenômenos naturais, ganhamos a possibilidade de estabelecermos o diálogo entre os conhecimentos tradicionais e os científicos. Um exemplo dessa proposição se dá quando se incluem, nos currículos, espaços para a instituição de práticas pedagógicas que utilizem como instrumento didático as histórias de vida dos sujeitos que compõem os grupos tradicionais. Ao registrarmos as memórias e as trajetórias de membros da comunidade, poderemos estabelecer vínculos dialógicos entre os diversos saberes que circulam na comunidade.

Com o estabelecimento desse diálogo com os saberes produzidos pelos sujeitos, podemos construir um movimento de ruptura com a lógica tradicional e rompermos com a ideia de que um conhecimento, para ser aceito como verdadeiro, deve passar por verificação e comprovação. $\mathrm{O}$ 
conhecimento popular ao entrar na sala de aula, a partir do registro das memórias e trajetórias, que pode ser realizado por meio do contato com os diversos grupos que compõem as comunidades tradicionais, estabelece uma outra lógica na construção do currículo, pois "dá voz" a saberes que tradicionalmente não têm espaço nas salas de aula.

O conteúdo programático dos currículos atuais reforça o modelo tradicional de ensino-aprendizagem, pois fragmenta os assuntos, compartimentalizando-os, não fazendo, assim, relação deles com a realidade e o cotidiano dos alunos. Por exemplo, o ensino das questões ambientais é trabalhado linearmente, numa complexificação crescente, porém segmentada, que vai do estudo de fatores bióticos e abióticos até os ecossistemas. Mas não vemos, quase nunca, uma relação entre esses assuntos e a vida dos alunos e até mesmo das nossas, pois se trabalha cada parte do ambiente, isoladamente, sem relação nem contexto.

A interdependência dos elementos que compõem o ambiente é posta de lado, em nome da especialização científica e saberes produzidos por outros grupos que não são, em nenhum momento, mencionados como parte deste conjunto, o qual chamamos ambiente.

Mas, é esta realidade que podemos comprovar no cotidiano dos grupos tradicionais? O sistema de ensino promove mudanças de hábitos, comportamentos e concepções nos indivíduos?

No dia a dia do trabalho com as comunidades tradicionais, vemos que o conhecimento científico é um elemento que passa por suas vidas através de uma espécie de filtro de seus próprios saberes, gerando um outro conhecimento, misto do científico e do popular. Como nos mostram Boaventura de Sousa Santos (1993) e Carlo Ginzburg (1987) há uma circularidade entre o conhecimento científico e o popular, que acaba por gerar uma outra forma de conhecimento. O ideal seria que pudéssemos caminhar no sentido de tornarmos uma prática comum a realização da "dupla ruptura epistemológica”, onde após rompermos com o senso comum (1. ${ }^{a}$ ruptura), rompêssemos com o conhecimento cientificamente elaborado ( $2 .^{\mathrm{a}}$ ruptura), de forma a organizarmos um conhecimento realmente válido nesses espaços multiculturais.

Nesse sentido, poderemos estabelecer um segundo movimento, em que o conhecimento profundo da realidade das comunidades fosse mais um elemento a compor o currículo. Ao invés de partirmos de uma lógica em que o conhecimento científico é apresentado muitas vezes como ver- 
dade única e absoluta, poderíamos partir dos conhecimentos produzidos pelas comunidades. O que esses grupos sabem e produzem cotidianamente? Esses conhecimentos e concepções podem se constituir em ponto de partida para que estabeleça o conhecimento cientifico escolar e, para isso, seria necessário um movimento de "saída da sala de aula" em que a realidade imediata das comunidades servisse de espaço de investigação para alunos e professores.

Muitas vezes o currículo tradicional limita o movimento de saída da escola e o entorno acaba se tornando um exemplo distante. O reconhecimento das comunidades, vivenciando organicamente seus cotidianos, é um campo fértil para que se entendam a lógica e a construção de conhecimentos. É por meio de uma vivência real que a sala de aula pode ampliar seus limites para além das quatro paredes e constituir-se como um espaço multicultural em que apenas não se fale do entorno, mas que se vivencie a realidade.

Mas, a realidade que vemos é outra: um sistema de ensino que se encontra em acelerado sucateamento e que não leva em consideração o saber popular e o saber dos alunos e alunas, nem dos grupos sociais aos quais pertencem, e reafirmam o discurso científico hegemônico.

Em nossa conjuntura atual, vemos que a escola perdeu o seu papel de transmissora e produtora de conhecimento, de formadora de cidadãos, no amplo sentido da palavra, e dirigiu seus objetivos para a produção de profissionais enquadrados ao mercado:

O que se observa hoje é que o Estado e a Sociedade Civil esperam da escola não a formação do homem-cidadão, plenamente desenvolvido como agente político e produto-produtor da cultura, mas $\operatorname{sim}$ a produção do profissional eficiente, o ser economicamente viável. $\mathrm{O}$ sistema educacional é diariamente pressionado a adequar o currículo escolar às necessidades do mercado de trabalho [...] hoje, todo ensino é, de certa maneira, profissionalizante, na medida em que para o indivíduo frequentar a escola se justifica apenas como um pré-requisito para a entrada no mercado de trabalho. O conhecimento, a cultura, nada tem valor, se não está diretamente articulado à produção. Tudo que excede a esta necessidade deve ser retirado do currículo escolar (Modesto, 1996, p. 79, grifo nosso). 
Este conhecimento trabalhado na escola reflete a formação cartesiana da sociedade, onde o mundo e suas relações podem ser comparados ao funcionamento de uma máquina, o corpo é separado da mente, a lógica matemática e econômica se sobrepõe à subjetividade dos seres humanos e suas relações. O currículo escolar, de uma maneira geral, trabalha a partir de uma base cartesiana, que leva a um conhecimento fragmentado de tal forma que fica difícil os alunos realizarem conexões entre os mesmos e entre esse conhecimento e a sua vida.

Além disso, o saber desses alunos é ignorado, na maioria das vezes, em nome da validade do conhecimento científico. Esquece-se que "[...] a sabedoria popular [...] representa o uso da razão sob outro sistema muito mais empírico e simbólico, ao mesmo tempo, muito mais sapiencial e dialético que cartesiano e positivista” (Parker, 1996, p. 318).

Um trabalho que permita a construção da sala de aula como um espaço multicultural pode contribuir para que entendamos que "[...] o conhecimento científico não é o reflexo das leis da natureza [...] é necessário, portanto, que toda ciência se interrogue sobre suas estruturas ideológicas e seu enraizamento sócio-cultural” (Morin, 1996, p. 25).

Entendendo o currículo como um artefato social e cultural (Moreira e Silva, 1995), perguntamos: por que a visão de mundo encontrada nas comunidades tradicionais não é levada para dentro da escola como material sócio-cultural a ser trabalhado? Continuamos a tratar o mundo, os seres humanos, a partir de uma visão asséptica, científica, enquanto fora da escola nossos alunos e até nós mesmos encaramos uma vida diferente daquela apresentada nas salas de aula.

As comunidades tradicionais buscam soluções para suas vidas, e as salas de aula precisam se tornar um espaço privilegiado de construção do conhecimento, discussão crítica e, principalmente, formação de cidadania. Um trabalho de investigação que possibilite reflexão teórica e acadêmica e, ao mesmo tempo, assuma o ponto de vista e leve em consideração o saber popular, bem como o conhecimento sistematizado produzido pelos diversos grupos sociais das camadas populares, permitirá a materialização de um currículo mais orgânico.

Levando em consideração que os conhecimentos são diferentes - não hierarquicamente diferentes - devido a suas origens, suas histórias, devemos partir do conhecimento do outro, que, banhado pelo nosso, resultará num conhecimento verdadeiro, possibilitando às comunidades 
tradicionais formas de luta e superação da condição de subalternidade e reprodução digna de suas vidas.

Inferimos que a escola, por ser um elemento presente na vida cotidiana desses grupos, pode possibilitar a construção de espaços dialógicos, pois é possível que nos espaços escolares sejam estruturadas alternativas capazes de contribuir para a organização dos grupos sociais nos diversos espaços nos quais eles transitam e, principalmente, a valorização de seus conhecimentos

Reforçamos que partirmos da afirmação que as comunidades tradicionais produzem conhecimentos que devam ser integrados, pois "[...] a hipótese popular não desarticula causa e efeito [...]" (Peregrino, 1993, p. 79 apud Valla, 1996, p. 181). Podemos estar à frente, com o caminho para entendermos como essas classes "são capazes de produzir conhecimento, são capazes de organizar e sistematizar pensamentos sobre a sociedade" (Valla, 1996, p. 178). Só com o reconhecimento do saber popular, das formas organizadas e sistematizadas com as quais se apresenta o conhecimento produzido pelas camadas populares, poderemos elaborar caminhos que apontem para a construção de uma sociedade mais igualitária e efetivamente democrática.

Em nosso entendimento, um currículo só será realmente válido para as comunidades tradicionais, se delas partir e a elas chegar, pois um conhecimento que não respeite o saber popular, extremamente rico, não pode ter validade. Um currículo multicultural precisa se tornar um espaço de diálogo profundo entre conhecimentos que, ao se mesclarem, construam um conhecimento outro, misto dos anteriores, banhados nas histórias, nas vivências das pessoas.

Uma proposta metodológica e pedagógica que dê atenção às diversas trilhas percorridas pelo conhecimento das comunidades tradicionais e os diversos viéses traçados por este conhecimento, tantas vezes oprimido e impedido de se expressar, é aquela capaz de assumir que vivemos uma "crise de interpretação" (Valla, 1996) e que não basta usarmos apenas metodologias de simplificação do conhecimento científico para atuarmos com as comunidades.

As expressões da cultura popular são a prova de que a visão de mundo das comunidades tradicionais pode oferecer informações sobre a sua produção de conhecimento, sobre as alternativas usadas historicamente para a reprodução de sua vida. Para tal, é necessário fazermos “[...] o esforço 
necessário de compreender as condições e experiências de vida, como também a ação política da população seja acompanhada por uma maior clareza das suas representações e visões de mundo" (Valla, 1996, p. 182).

Nesse sentido, entendemos que a construção de um currículo multicultural, deve se dar cotidianamente, pautada em um diálogo profundo entre os saberes que circulam nas salas de aula. Colocamo-nos contrários à lógica que hierarquiza, apaga e silencia conhecimentos que não são considerados válidos e verdadeiros. Um currículo que faça sentido é aquele em que as comunidades tradicionais se reconheçam e que possam, a partir dele, ampliar sua visão de mundo.

\section{Referências}

ALBUQUERQUE, U. P. "Etnobotânica: uma aproximação teórica e epistemológica”. Revista Brasileira de Farmácia, v. 78, n. 3, pp. 60-4, Rio de Janeiro, 1997.

. "La importância de los estúdios etnobiológicos para estabelecimento de estratégias de manejo y conservación em las florestas tropicales". Biotemas, v. 12, n. 1, pp. 31-47, 1999.

BAPTISTA, G. C. S. "Importância da demarcação de saberes no ensino de Ciências para sociedades tradicionais". Ciência e educação, v. 16, n. 3, pp. 679-94, 2010.

CAPRA, F. O ponto de mutação. São Paulo: Ed. Cultrix, 1982.

CHARLOT, B. Da relação com o saber: elementos para uma teoria. Porto Alegre: Artes Médicas Sul, 2000.

CHASSOT, A. I. "Outro marco zero para uma história da ciência latino americana”. Quimica na Nova Escola, v. 7, n. 13, pp. 42-5, 2001.

COBERN, W. W. "Constructivism and non-western Science education research". International Journal of Science Education, v. 4, n. 3, pp. 287303, 1996.

DEMO, P. Desafios modernos da educação. 2 ed. Petrópolis: Vozes, 1993, 120p. 
DIEGUES, A. C. e ARRUDA, R.. S. V. (orgs.). Saberes tradicionais e biodiversidade no Brasil. Brasília: Ministério do Meio Ambiente; São Paulo: USP, 2001.

FREIRE, P. Pedagogia do oprimido. São Paulo: Ed. Paz e Terra, 1993.

GINZBURG, C. O queijo e os vermes: o cotidiano e as idéias de um moleiro perseguido pela Inquisição. São Paulo: Ed. Companhia das Letras, 1987.

GUIMARÃES, M. A dimensão ambiental na educação. Campinas: Papirus, 1995, 107p.

LOPES, A. R. C. Conhecimento escolar: ciência e cotidiano. Rio de Janeiro: EdUERJ, 1999.

LUZZI, D. "A 'ambientalização' da educação formal: um diálogo aberto na complexidade do campo educativo". In LEFF, E. (coord.). A complexidade ambiental. São Paulo: Cortez, 2003, pp. 178-216.

MARTINS, J. S. Exclusão social e nova desigualdade. São Paulo: Ed. Paulus, 1997.

MOREIRA, A. F. e SILVA, T. T. Curriculo, cultura e sociedade. São Paulo: Ed. Cortez, 1995.

MORIN, E. Ciência com consciência. Rio de Janeiro: Ed. Bertrand Brasil, 1996.

PARÉ, M. L. et al. "A educação para quilombolas: experiências de São Miguel dos pretos em restinga seca (RS) e da comunidade Kalunga do Engenho II (GO)”. Cad. Cedes, v. 27, n. 72, pp. 215-32, Campinas, 2007.

PARKER, C. Religião Popular e modernização capitalista: outra lógica na América Latina. Petrópolis: Ed. Vozes, 1996.

PAVAN-FRUEHAUF, S. Plantas medicinais de Mata Atlântica: manejo sustentado e amostragem. São Paulo: Annablume, Fapesp, 2000.

PERRELLI, M.A.S. Conhecimento tradicional e curriculo multicultural, ciência e educação, v. 14, n. 3, pp. 381-96, 2008.

e MORAES, M. G. "Etnociências aplicadas como ferramenta para educação ambiental: resgatando os saberes complexos”. p. 59-69. In GUIMARÃES, M. e FONSECA, L. Educação em ciências e educação am- 
biental - caminhos e confluências. 1 ed. Seropédica, RJ: EDUFRRJ, 2012, pp. 59-69.

QUINTEIRO, M. M. C. et al. "Formas de retorno da pesquisa etnobotânica à comunidade no paradigma da complexidade ambiental e educação ambiental”. Revbea, v. 8, n. 1, pp. 91-9, 2013.

RESENDE, D. R. et al. “O saber popular nas aulas de Química: relato de experiência envolvendo a produção do vinho de laranja e sua interpretação no ensino médio". Química Nova na Escola, v. 32, n. 3, pp. 151-60, 2010.

RIOJAS, J. "A complexidade ambiental na universidade”. In LEFF, E. (coord.). A complexidade ambiental. São Paulo: Cortez, 2003, pp. 216-38.

SANTOS, B. S. Introdução a uma ciência pós-moderna. Porto: Ed. Afrontamento, 1993.

SEVERI, C. 2009. "A palavra emprestada ou como falam as imagens". Revista de Antropologia, v. 52, n. 2, pp. 459-506, USP, 2009.

SOUTHERLAND, S. A. "Epistemic universalismand the shortcomings of curricular multicultural science education". Scinece \& Education, v. 9, n. 3, pp. 289-307, 2000.

TASSINARI, A. M. I. "Escola indígena: novos horizontes teóricos, novas fronteiras de educação”. In SILVA, A. L. e FERREIRA, M. K. L. Antropologia, história e educação: a questão indígena e a escola. 2 ed. São Paulo: Global, 2001.

VALLA, V. V. "A crise de interpretação é nossa: procurando compreender a fala das classes subalternas". Revista Educação e Realidade., v. 21, n. 2, pp. 177-90, Porto Alegre, 1996. 